\title{
Prediction of combined effects of fibers and nano- silica on the mechanical properties of self-compacting concrete using artificial neural network
}

\begin{abstract}
In this research, the combined effect of nano-silica particles and three fiber types (steel, polypropylene and glass) on the mechanical properties (compressive, tensile and flexural strength) of reinforced self-compacting concrete(SCC) is evaluated. For this purpose, 70 mixtures in A, B, C, D, E, F and G series representing $0,1,2,3,4,5$ and 6 percent of nano-silica particles in replacing cement content are cast. Each series involves three different fiber types and content; $0.2,0.3$ and $0.5 \%$ volume for steel fiber, $0.1,0.15$ and $0.2 \%$ of volume for polypropylene fiber and finally $0.15,0.2$ and $0.3 \%$ of volume for glass fiber. The results show that the simultaneous usage of an optimum percentage of fiber and nano-silica particles will improve the mechanical properties of SCC. Moreover, the obtained results from the experimental data are used to train a multi-layer perceptron (MLP)type artificial neural network(ANN). The trained network is then used to predict the effect of various parameters on the desired output namely the flexural tensile strength, tensile strength behavior and compressive strength.
\end{abstract}

\section{Keywords}

Fiber, Self-compacting concrete, Nano-silica, mechanical properties, artificial neural network.

\author{
Hamid Reza Tavakoli ${ }^{\text {* }}$ \\ Omid Lotfi Omran ${ }^{\text {b }}$ \\ Masoud Falahtabar shiade \\ Saman Soleimani Kutanaei ${ }^{d}$ \\ ${ }^{\text {a }}$ Assistant Professor, Department of \\ Civil Engineering, Babol University of \\ Technology, Babol, IRAN, P.O.Box \\ 484. E-mail: tavakoli@nit.ac.ir \\ ${ }^{\mathrm{b}}$ Young Researchers Club, Qaemshahr \\ Branch, Islamic Azad University Qa- \\ emshahr, Iran E-mail: \\ Omid_saze_civil@yahoo.com \\ ${ }^{\mathrm{c}}$ MS Student, Department of Civil \\ Engineering, Babol University of \\ Technology, Babol, IRAN, P.O.Box \\ 484. E-mail: m_falah_tsh@yahoo.com \\ ${ }^{\mathrm{d}}$ Department of Engineering seismology \\ and risk, Road, Housing and Urban \\ Development Research Center (BHRC), \\ Tehran, P.O. Box: 13145-1696, Iran \\ E-mail: samansoleimani16@yahoo .com \\ * Corresponding author. Tel.: +98111 \\ 3231703.
}

\section{INTRODUCTION}

Self-compacting concrete (SCC) was first developed to improve durability and stability of concrete structures in Japan in 1988 (Ozawa et al., 1996). Preliminary studies about workability of SCC were carried out by Ozawa (1989) and Okamura (1993) in Tokyo University (Okamura, 1997; Okamura and Ozawa, 1994). However, concrete is not suitable for most structures such as bridges, 
dams and airports because of its low tensile strength resulting a weak formation and high brittleness. To overcome the above barriers, concrete reinforcing steel has been used in various types of structures. Although these bars are centrally placed in concrete and compensate the weakness to high extent, they are expensive and cannot be applied in some cases such as surface of canals and airports overlays. A number of studies have been conducted relating to the behavior of concrete reinforced with randomly distributed fibers under static and dynamic loading conditions (Xu et al., 2012; Amr, 2009; Holschemacher et al., 2010; Al-Rousan, 2013; Majid et al., 2013; Ivorra et al., 2010; Tumadhir, 2012; Xua and Haoa, 2012; Huang and Zuo, 2005; Beigi et al., 2013).

During the last decades string fibers have been used in concrete to solve the aforementioned problem. Rupture of concrete drastically depends on crack formation due to loading or environmental impacts. Variations in temperature and humidity cause microscopic cracks in mortar which centralize on the surface of coarse aggregates. Continuous loading causes the cracks propagate throughout the concrete (Soroushian, 1986). Using different reinforcing fibers in concrete to make Fiber Reinforced Concrete (FRC) is one of the effective methods to prevent crack propagation and compensating the shrinkage induced by low tensile strength of concerts (Seung et al., 2012). The most important properties of fiber concrete are energy absorption, formability and resistance against strikes. These characteristics help FRC to play an important role in concrete technology and to be a cost-effective material in structural issues (Lin, 1992; Su-Taekang et al., 2010; Olivito and Zuccarello, 2010; Seddik and Bencheikh, 2009; Mohammadi et al., 2009; Bencardino et al., 2010). Energy absorption and strengthening of concrete can efficiently reduce the rupture risk in concrete structures, especially under alternative and vibrating loads. It is worth noting that rupture strain for a brittle matrix (like Portland cement), is much less (less than 1.5) than that of a strong fiber (like steel, glass and polypropylene). Therefore, when FRC is subjected to impact loading, cracks occurrence in matrix is much faster than the rupture occurrence in fibers. Contact area which is also called border layer, is a border area between mortar and the surface of aggregates or fibers or reinforcing bars which plays an important role in permeability, durability and strength of concrete.

Micro-structural characteristics of this area are quite different from mortar containing more pores and micro-cracks. Thickness of contact area depends on the type of fibers, cement, pozzolanic material, water/cement ratio and also concrete age. In this experimental study nano-silica was used as an artificial pozzolan to reinforce the contact area. The addition of nano- $\mathrm{SiO}_{2}$ into concrete mixtures has been studied by a number of researchers (Qing et al., 2007; Collepardi et al., 2007; Naji et al., 2011; Nazari and Shadi Riahi, 2011; Shekari and Razzaghi, 2011; Tavakoli et al., 2014). Therefore, nano-silica can increase compressive strength of mortar and bonding strength of mortaraggregates and mortar-fibers interfaces; resulting in an improvement in the structural properties of contact area.

Artificial neural networks (ANN)were previously used to predicting the concrete properties (Flood et al., 2001; Pannir selvam et al., 2008; Perera et al., 2010; Yang et al., 2008; Guang and Zong, 2000; Goh ATC, 1995; Sanad and Saka, 2001; Jamal et al., 2007; Arslan, 2009; Arslan et al., 2007).From a literature study it could be find that there is no investigation on the combined effects of fibers and nano-silica on the mechanical Properties of SCC using ANN. 
In this study, the obtained results from the experimental data are used to train the MLP type of ANN. To train the present MLP-ANN; the percentage of nano particles and fiber as the inputs and flexural tensile strength, tensile strength behavior and compressive strength as the outputs of the network are used. The trained network is then used to predict the effect of various parameters on the desired output.

\section{MATERIAL PROPOERTIES AND EXPERIMENTAL SETUP}

\subsection{Material}

To carry out the experimental Investigation, an amorphous nano-silica (nano-SiO2, Meyco MP320, BASF) with a solid content of more than $99 \%$ is used. Physical properties of these materials are shown in table (1). The nano-silica content for different cases was 2, 4, and $6 \mathrm{wt} \%$. In this study, a super plasticizer (SP) of carboxylic ether (Glenium-110P, BASF) with specific gravity $1.1 \mathrm{gr} / \mathrm{cm} 3$ (at $20^{\circ} \mathrm{C}$ ) and three types of reinforcing fibers namely polypropylene (PP fibers, peypolsazan), stainless steel (DUOLOC 36/0.8,BASF) and glass (Chopped Strand, bloorintar) (See Fig.(1)and Table (2)) were used.

\begin{tabular}{llll}
\hline \hline $\begin{array}{l}\text { Diameter } \\
(\mathrm{nm})\end{array}$ & $\begin{array}{l}\text { Surface- volume } \\
\text { ratio }(\mathrm{m} 2 / \mathrm{g})\end{array}$ & $\begin{array}{l}\text { Density } \\
\left(\mathrm{g} / \mathrm{cm}^{3}\right)\end{array}$ & $\begin{array}{l}\text { Purity } \\
(\%)\end{array}$ \\
\hline $15 \pm 5$ & $160 \pm 20$ & $<0.15$ & $>99.9$ \\
\hline \hline
\end{tabular}

Table 1: Properties of nano-Silica.

\begin{tabular}{lllllll}
\hline \hline Type & $\begin{array}{l}\text { Length } \\
(\mathrm{mm})\end{array}$ & $\begin{array}{l}\text { diameter } \\
(\mathrm{mm})\end{array}$ & $\begin{array}{l}\text { Tensile strength } \\
(\mathrm{MPa})\end{array}$ & $\begin{array}{l}\text { Aspect ratio } \\
l / d\end{array}$ & $\begin{array}{l}\text { Elastic modulus } \\
(\mathrm{GPa})\end{array}$ & $\begin{array}{l}\text { Density } \\
\left(\mathrm{g} / \mathrm{cm}^{3}\right)\end{array}$ \\
\hline Steel & 36 & 0.7 & 2100 & 50 & 160 & 7.8 \\
polypropylene & 12 & 0.1 & 450 & 120 & 5 & 0.9 \\
Glass & 12 & 0.1 & 1400 & 600 & 87 & 2.65 \\
\hline \hline
\end{tabular}

Table 2: Properties of the reinforcing fibers.
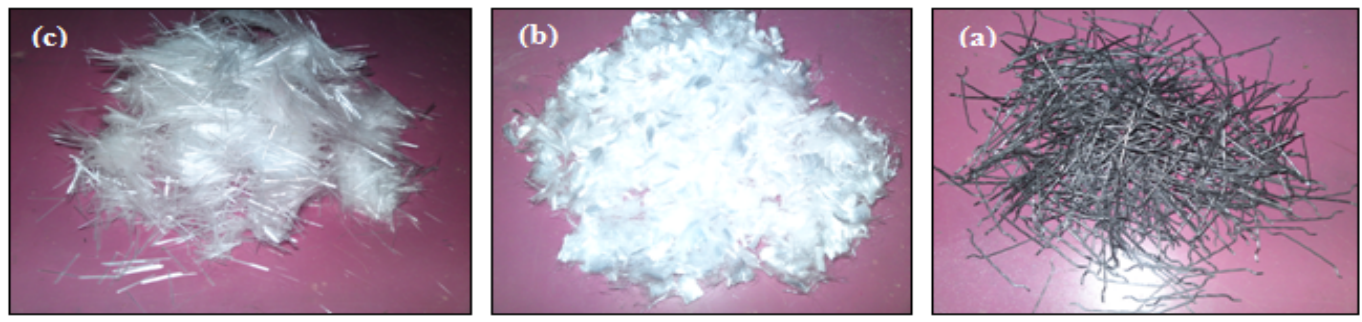

Figure 1: Different types of fibers used in this investigation: (a) steel, (b) polypropylene, (c) Glass.

The size of gravel was less than $12.5 \mathrm{~mm} 3$ and in accordance with ASTM standard of grading curve. The sand was selected from sieve No. $4.75 \mathrm{~mm}$ equivalent to 76 -percent sand. Cement was of Portland type II and specific gravity of limestone powder was $2.6 \mathrm{gr} / \mathrm{cm} 3$. 
In the present work seventy mixtures in A, B, C, D, E, F and G categories representing 0, 1, 2, $3,4,5$ and 6 percent of nano-silica particles replacing cement content were cast. Each series involves three different fiber type and content;0.2, 0.3 and $0.5 \%$ volume for steel fiber, $0.1,0.15$ and $0.2 \%$ of volume for polypropylene fiber and finally $0.15,0.2$ and $0.3 \%$ of volume for glass fiber. In all 70 samples, all variables were the same except for the fiber type and contents of fibers and nanosilica. The sample with Water/cement (nano-silica + cement) ratio of 0.39 and the sample with no fibers and nano-silica were considered as the control sample (Vf in Table (3) is the volume percent of fiber, i.e. fiber to concrete volume ratio).

\subsection{Curing and maintaining the samples}

Once the mixing process was completed, the samples were placed into molds and kept under laboratory condition for 24 hours. They were then removed from the molds and kept in $22-25^{\circ} \mathrm{c}$ water until the suitable age (28 days) for each experiment. Each mixing design included nine $100 \times 100 \times 100 \mathrm{~mm}$ cubic molds, six $300 \times 150 \mathrm{~mm}$ cylindrical molds and three $500 \times 100 \times 100 \mathrm{~mm}$ beam molds. There were a total of 1260 samples for 70 mix design protocols.

\subsection{Experimental setup}

Compressive strength test was conducted according to the standard B.S1881:Part116. In these assessments, curing condition and experimental and the sample production parameters were the same. Tensile strength test was used, according to the standard ASTM C496 to determine concrete splitting tensile strength. Flexural strength test was performed on a hydraulic Universal Testing Machine (UTM) equipped with displacement speed Control mechanism (displacement rate of 0.5 $\mathrm{mm} / \mathrm{min}$ ) according to the standard ASTM C1018-94b. The samples were $100 \times 100 \times 500 \mathrm{~mm}$ prismatic mixes. The distance between the two supports was $40 \mathrm{~cm}$.

\section{ARTIFICIAL NEURAL NETWORKS (ANN)}

\subsection{Modeling using MLP-type neural networks}

Unknown function approximation has attracted a great deal of research from different areas such as statistic, data mining, and engineering sciences. Among various types of function approximation tools, artificial neural networks provide a framework which can learn or approximate any function from given data samples through a training process. One of the most important features of a neural network is its flexibility and ability to learn complicated relationships based on the data. Various neural network architectures exist, of which the most popular is the feedforward multi-layer perceptron (MLP). An MLP type of neural network consists of one input layer; one or more hidden layer(s) and one output layer with a large number of inter connected neurons. Fig. (2) shows the basic structure of a typical MLP network.

An example of a MLP type of neural network with one input node, a single hidden layer with two neuron and one output neuron is shown in Fig.(3). An additional input called bias with constant value of 1 is added to the previous input node which works as a shift operator. Each input 
node is related to each neuron in hidden layer by a connecting weight. The sum of the products of the weights and the inputs is calculated by each neuron in hidden layer and then treated by an activation function. The obtained result is then multiplied by the associated weight $C_{3}$ and again the previous procedure will be repeated in the output neuron. In the present study hyperbolic tangent and linear functions are used as the activation functions in the hidden and output layers respectively.

The final output of the current network is calculated as

$$
\operatorname{Network~output}(N O)=F_{1}\left(x_{1}\right)+F_{2}\left(x_{1}\right)=F\left(x_{1}\right)
$$

where,

$$
F_{1}\left(x_{1}\right)=C_{3} \tanh \left(C_{1} x_{1}+C_{2}\right)
$$

Once the number of layers and the number of neurons in each layer, have been selected, the network's weights must be adjusted to minimize the prediction error made by the network. This is the general role of the training algorithms. In this investigation Back-propagation (BP) method is applied to train the ANN which is the most widely used learning process in neural networks today.

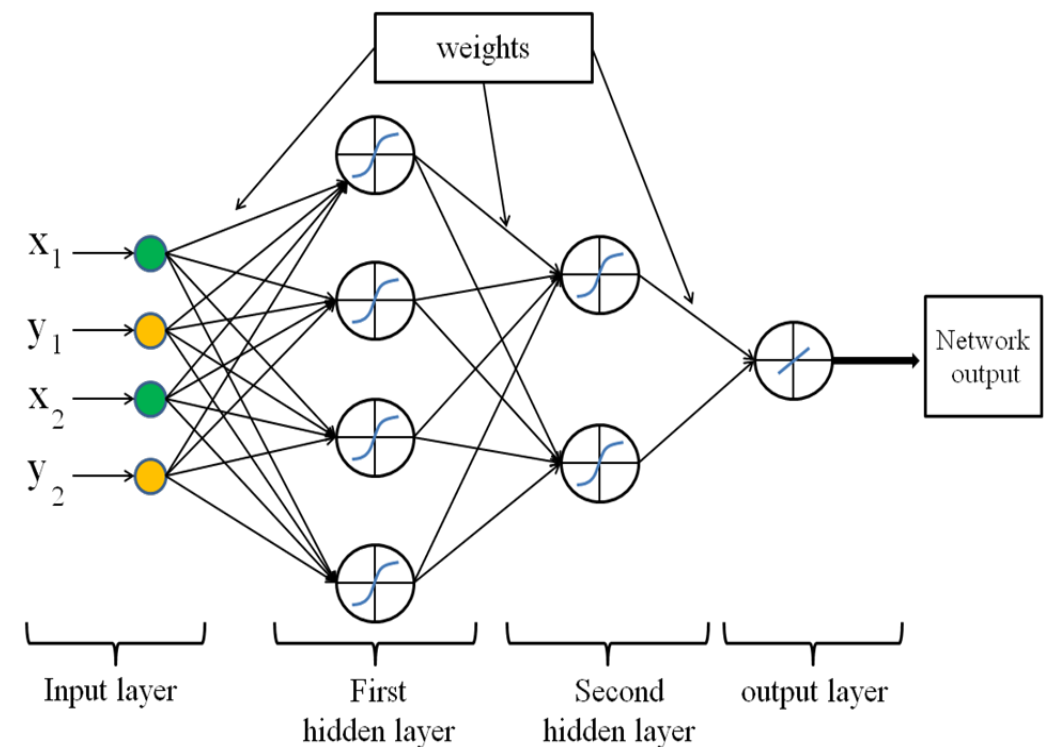

Figure 2: The structure of an MLP-type network.

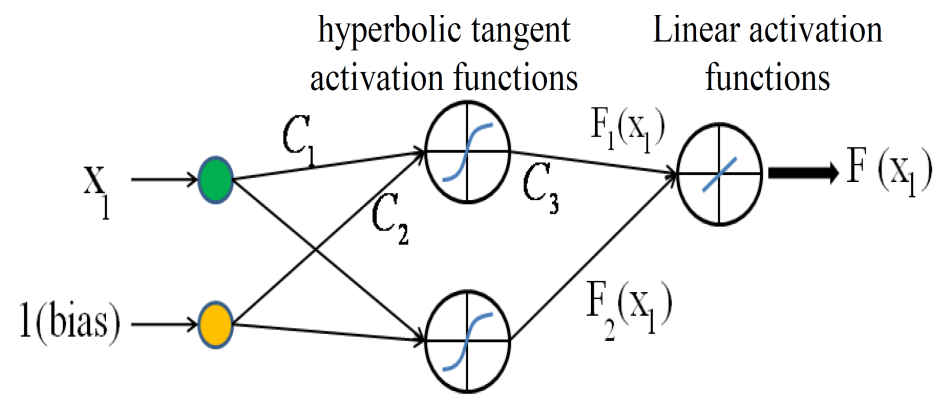


Figure 3: Architecture of a network with one hidden layer containing two neurons and one neuron in the output layer.

\subsection{Back-Propagation algorithm}

Back-propagation was firstly proposed by Werbos (Werbos, 1974) which is based on searching an error surface (error as a function of ANN weights) using the gradient descent algorithm for points with minimum error.

Consider a network with one hidden layer and one output neuron as shown in Fig (4).

When a set of input data (input vector) are propagated through the network, for the current set of weights there is an output Est. The training of perceptron is a supervised learning algorithm where weights are adjusted to minimize the absolute error between the estimated output Est of network and the desired output Des whenever the estimated output does not match the desired output. If the network error $(N E)$ is defined as:

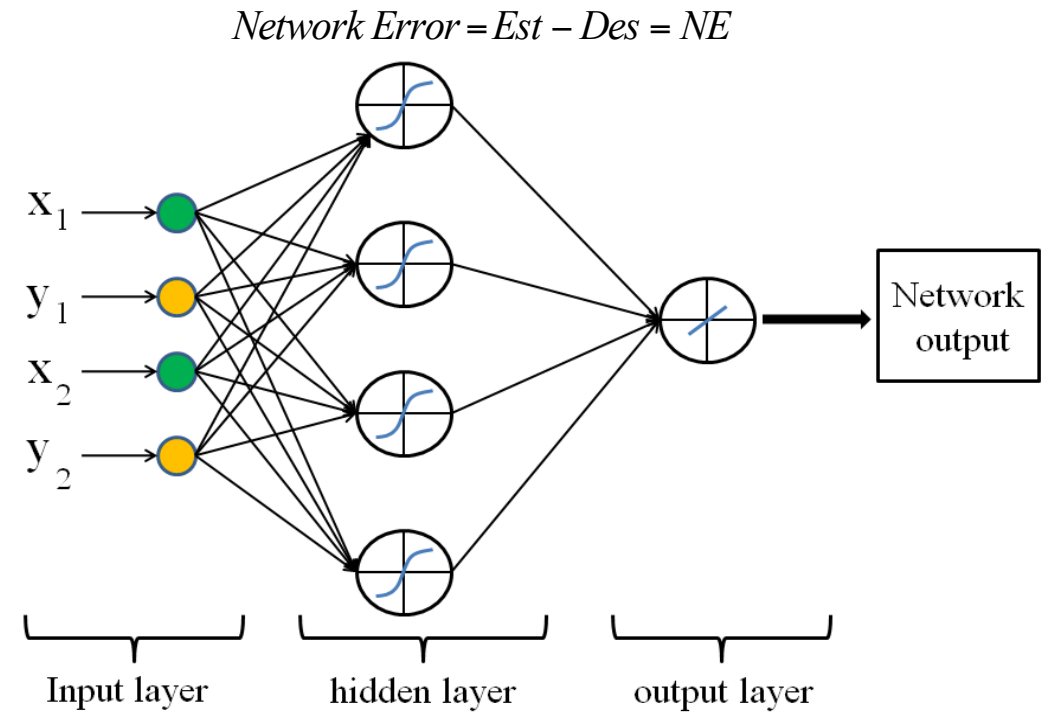

Figure 4: A feed-forward multi-layer perceptron type of neural network with one hidden layer.

The training algorithm should adjust the weights to minimize $N E^{2}$. For this purpose an artificial neuron with its basic elements is considered as shown in Fig .(5). The neuron consists of three basic components; weights, a summing junction and an activation function. 


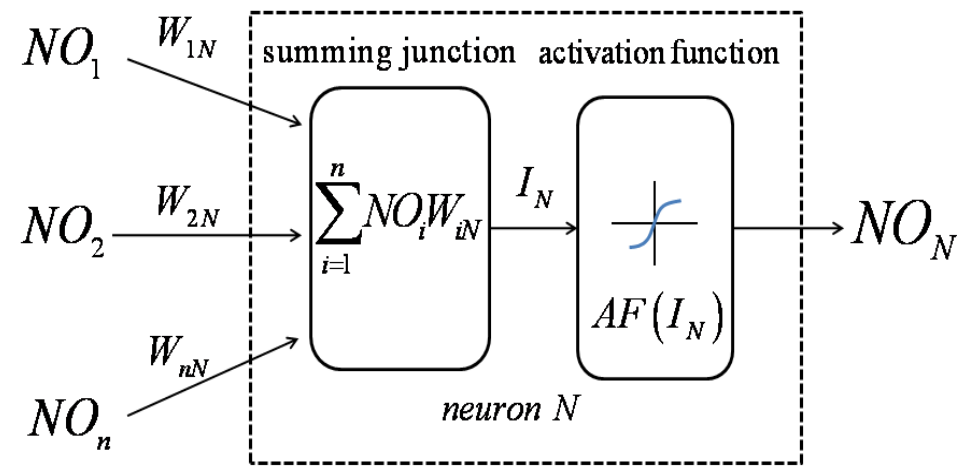

Figure 5: Basic elements of an artificial neuron

The outputs of $n$ neurons $N O_{1}, \ldots, N O_{n}$ lead in neuron $N$ as the inputs. If neuron $N$ is in the hidden layer then this is the input vector of the network. These outputs are multiplied by the associated weights $W_{1 N}, \ldots, W_{n N}$. The summing junction adds together all these products to provide the input $I_{N}$ for activation function of neuron $N$. Then $I_{N}$ passes through the activation function $A F()$ and gives the final output of neuron $N$, which is $N O_{N}$.

To commence the calculations, consider neuron $M$ and weight $W_{M N}$ which connects the two neurons. The equation for weight update is as follows

$$
W_{M N \text { (adjusted) }}=W_{M N(\text { old })}-L R \cdot \frac{\partial\left(N E^{2}\right)}{\partial W_{M N}}
$$

where $L R$ is the learning rate parameter and $\partial(N E)^{2} / \partial W_{M N}$ is error gradient with reference to the weight $W_{M N}$. The chain rule gives

$$
\frac{\partial\left(N E^{2}\right)}{\partial W_{M N}}=\frac{\partial\left(N E^{2}\right)}{\partial I_{N}} \frac{\partial I_{N}}{\partial W_{M N}}
$$

since the rest of the inputs to neuron $N$ are independent of the weight $W_{M N}$ we have

$$
\frac{\partial I_{N}}{\partial W_{M N}}=\frac{\partial \sum_{i=1}^{n} N O_{i} W_{i N}}{\partial W_{M N}}=\frac{\partial N O_{M} W_{M N}}{\partial W_{M N}}+\frac{\partial \sum_{i=2}^{n} N O_{i} W_{i N}}{\partial W_{M N}}=N O_{M}
$$

Eqs. (4), (5) and (6) give

$$
W_{M N \text { (adjusted) }}=W_{M N \text { (old) }}-L R \cdot \frac{\partial\left(N E^{2}\right)}{\partial I_{N}} N O_{M}
$$

For the case $N$ is an output neuron we have:

$$
\begin{aligned}
& \partial\left(N E^{2}\right)=\partial(E s t-D e s)^{2} \longrightarrow \\
& \frac{\partial\left(N E^{2}\right)}{\partial I_{N}}=2(E s t-D e s) \frac{\partial E s t}{\partial I_{N}}=2(N E) \frac{\partial A F\left(I_{N}\right)}{\partial I_{N}}=2(N E) \times A F^{\prime}\left(I_{N}\right)
\end{aligned}
$$

Substituting Eq. (8) into Eq. (7) gives 


$$
W_{M N(\text { adjusted })}=W_{M N(\text { old })}-L R \cdot N O_{M} \cdot 2(N E) \times A F^{\prime}\left(I_{N}\right)
$$

For hyperbolic tangent and linear activation functions $A F^{\prime}\left(I_{N}\right)$ and the final form of weight update rule can be written as follows

$$
\begin{gathered}
\text { For hyperbolic tangent: }\left\{\begin{array}{l}
A F^{\prime}\left(I_{N}\right)=1-\left[A F\left(I_{N}\right)\right]^{2} \longrightarrow \\
W_{M N(\text { adjusted })}=W_{M N(\text { old })}-L R \cdot N O_{M} \cdot 2(N E) \times\left(1-\left[A F\left(I_{N}\right)\right]^{2}\right)
\end{array}\right. \\
\text { for linear functions: }\left\{\begin{array}{l}
A F^{\prime}\left(I_{N}\right)=1 \\
W_{M N(\text { adjusted })}=W_{M N(\text { old })}-L R \cdot N O_{M} \cdot 2(N E)
\end{array}\right.
\end{gathered}
$$

When $N$ is a hidden layer neuron

$$
\frac{\partial(N E)^{2}}{\partial I_{N}}=\frac{\partial\left(N E^{2}\right)}{\partial I_{o n}} \frac{\partial I_{o n}}{\partial N O_{N}} \frac{\partial N O_{N}}{\partial I_{N}}
$$

where the subscript on represents the output neuron. In Eq. (12) we have

$$
\begin{aligned}
\frac{\partial N O_{N}}{\partial I_{N}}= & \frac{\partial A F\left(I_{N}\right)}{\partial I_{N}}=A F^{\prime}\left(I_{N}\right), \\
\frac{\partial I_{o n}}{\partial N O_{N}} & =\frac{\partial \sum_{i} N O_{i} W_{i o n}}{\partial N O_{N}}=\frac{\partial N O_{N} W_{N o n}}{\partial N O_{N}}+\frac{\partial \sum_{i}^{i \neq N} N O_{i} W_{i o n}}{\partial N O_{N}}=W_{N o n}
\end{aligned}
$$

substituting Eq. (13) into Eq. (12) gives

$$
\frac{\partial\left(N E^{2}\right)}{\partial I_{N}}=\frac{\partial\left(N E^{2}\right)}{\partial I_{o n}} W_{N o n} \times A F\left(I_{N}\right)
$$

In Eq. (14), $\partial\left(N E^{2}\right) / \partial I_{N}$ is now written as a function of $\partial\left(N E^{2}\right) / \partial I_{o n}$ which was calculated in Equation (8).

Hence the weight update rule for a hidden layer neuron takes the following form

$$
W_{M N(\text { adjusted })}=W_{M N(\text { old })}-L R \cdot N O_{M} \frac{\partial\left(N E^{2}\right)}{\partial I_{o n}} W_{N o n} \times A F\left(I_{N}\right)
$$

\subsection{Performance of neural network}

The most common parameters for evaluation of a neural network's performance are minimum total squared errors (or RMS error) and minimum total absolute error [DTI, 1994] (or MAE error). MAE and RMS errors are defined as

$$
\text { RMS error: } \sqrt{\frac{\sum_{i=1}^{n}\left(D e s_{i}-E s t_{i}\right)^{2}}{n}}
$$


MAE error:

$$
\frac{\sum_{i=1}^{n}\left|D e s_{i}-E s t_{i}\right|}{n}
$$

where $n$ is the number of training data. The number of hidden layers and the neurons in each of them should be determined in a way to minimum the above errors.

\section{RESULTS AND DISCUSSION}

\subsection{Compressive strength}

As seen in fig.(6a), the compressive strength initially increases as the content of fibers growth up to $0.3 \mathrm{v} \%$ while further increment in the value of fiber content up to $0.5 \mathrm{~V} \%$, decreases the compressive strength. As shown in fig. (6b)the compressive strength decrease as polypropylene fiber percent increases. In addition, an increasing trend in compressive strength Is observed in fig. (6c). This observation is consistent with those of Guang NH and Zong WJ [2000].

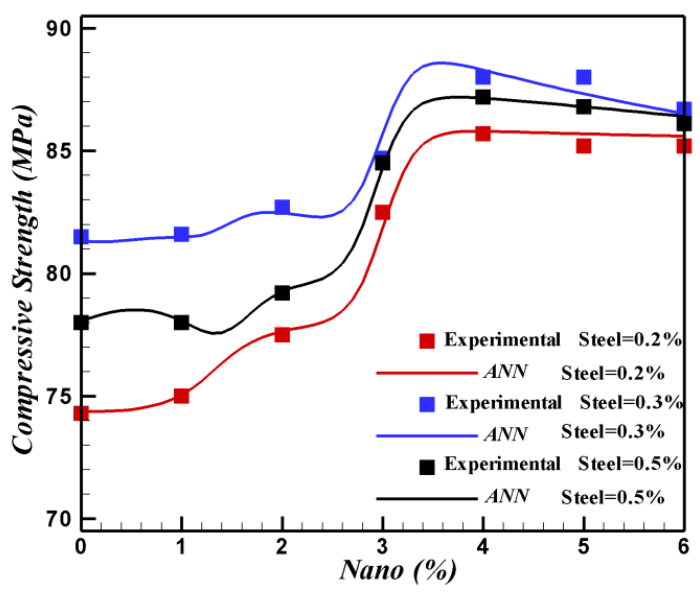

(a) Steel fibers.

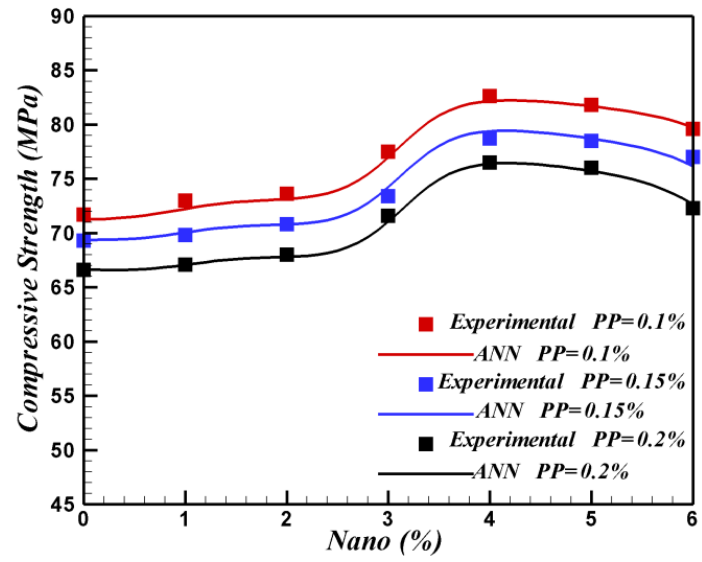

(b) PP fibers. 


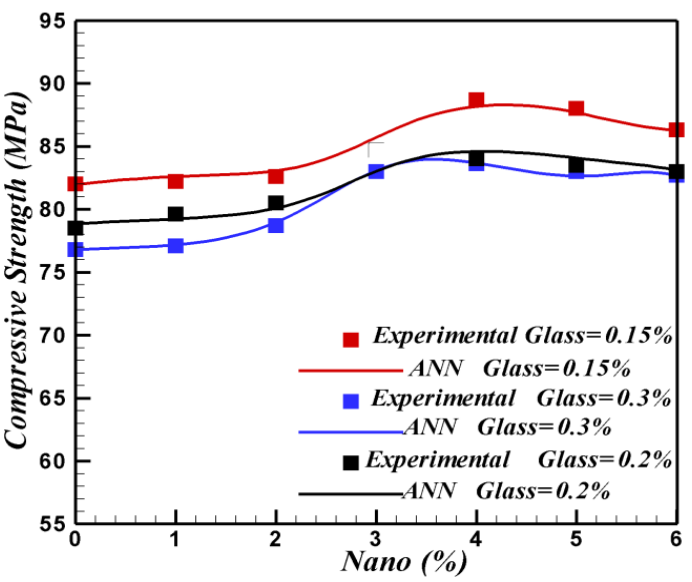

(c) Glass fibers.

Figure 6: Compressive strength of the samples containing: a) Steel fibers, b) PP fibers, c) Glass fibers.

\subsection{Splitting tensile strength}

Fig. (7) shows the tensile strength behavior of nano-silica-reinforced concrete with different contents of reinforcing fibers including steel, polypropylene and glass fibers. Stress-strain curves for all fibers show a relatively similar trend: An initial linear increasing trend which reaches to a maximum point, followed by a rather plateau section. This observation is consistent with those of Su-Tae Kang et al. (2010). An increase in the content of steel, polypropylene and glass fibers was accompanied by a $45 \%, 15 \%$, and $33 \%$ increase in tensile strength of the sample, respectively. However, addition of nanosilica to the sample, dramatically improved these increases so that tensile strength reached to $90 \%, 57 \%$ and $77 \%$, respectively. This improvement can be attributed to the larger contact area between fibers and mortar resulting in more friction and higher performance of the concrete. 


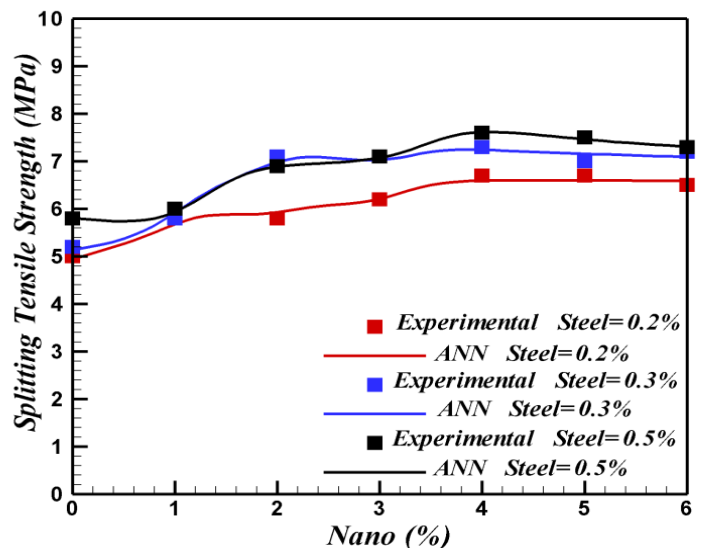

(a) Steel fibers.

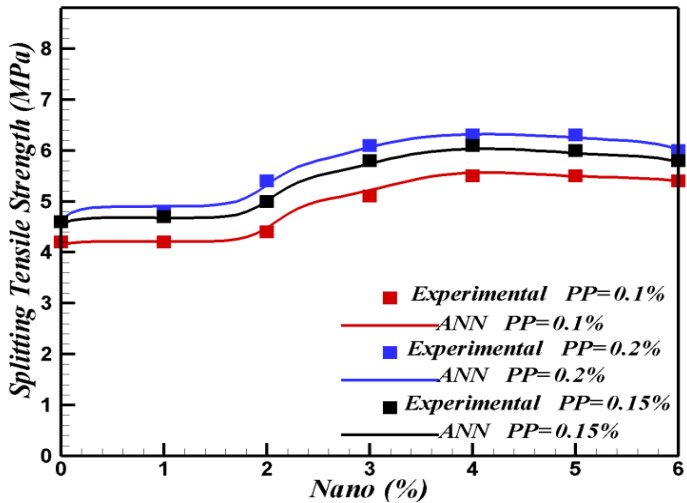

(b) PP fibers.

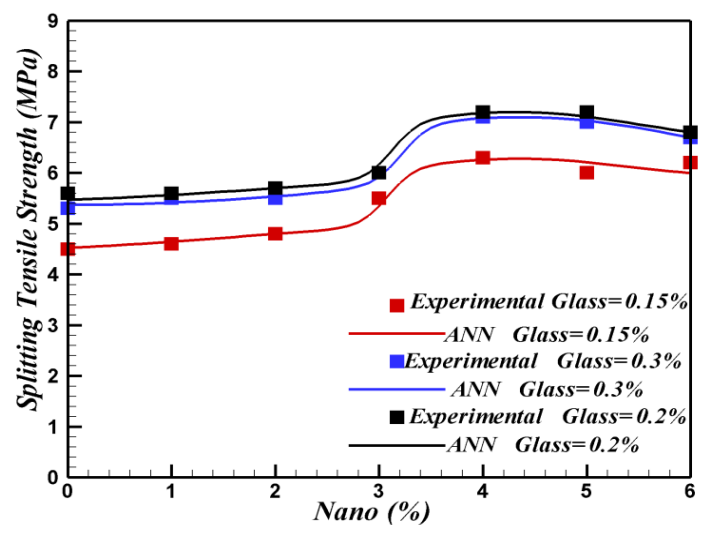

(c) Glass fibers.

Figure 7: Tensile strength of the samples containing: a) Steel fibers; b) PP fibers; c) Glass fibers.

\subsection{Flexural strength}

Fig.(8) shows a direct relationship between the flexural tensile strength and content of reinforcing fibers (steel, polypropylene and glass). Maximum increase in flexural strength equals 7.08, 6.6 and 8.1 $\mathrm{MPa}$ when there is an increase of $0.5 \mathrm{~V} \%$ in steel, $0.2 \mathrm{~V} \%$ in polypropylene and $0.2 \mathrm{~V} \%$ in glass fibers, respectively. The main important role of adding reinforcing fibers to concrete is making links between cracks produced by different causes. If the fibers in volume unit have enough density, strength and are well adhered to cement matrix, they can limit the spread of cracks and give the fiber-reinforced concrete efficient tolerance against greater stresses after the appearance of cracks. This also improves the formability of concrete after the appearance of cracks. For better understand the influence of nano-silica and fiber in mixture, force- deflection behavior of concrete mixtures without fiber are shown in Fig.(9). It can be observed that reinforced matrices exhibit high strength compared to un-reinforced matrix. As seen in the figure, with increasing in Percentage of fibers, 
peak load has risen and the softening branch, especially in beams containing steel fiber is developed. This could be due to reinforcement properties and bridging fibers, and consequently an increase in the tensile strength and flexural strength.

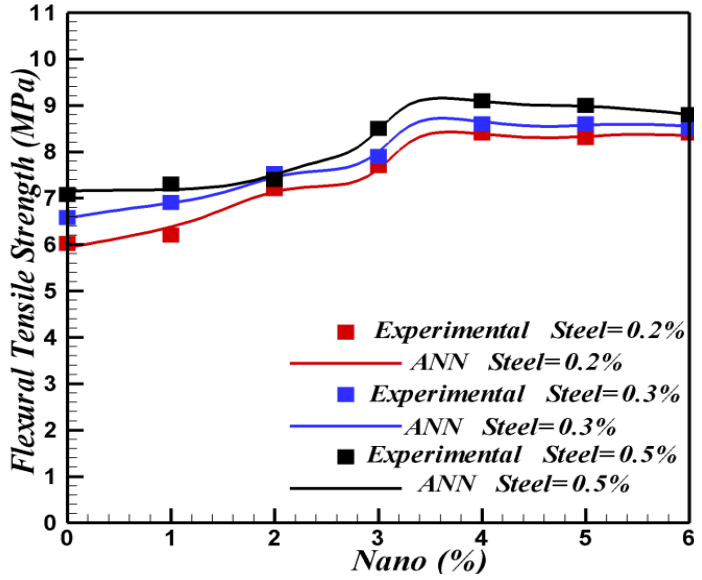

(a) Steel fibers.

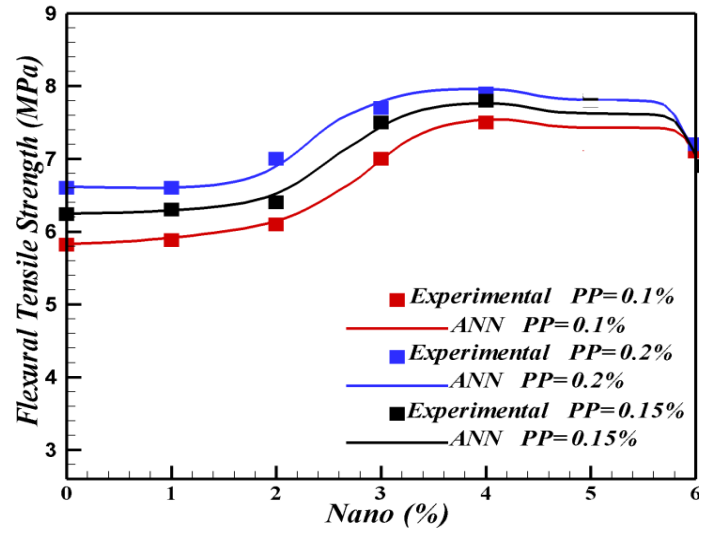

(b) PP fibers.

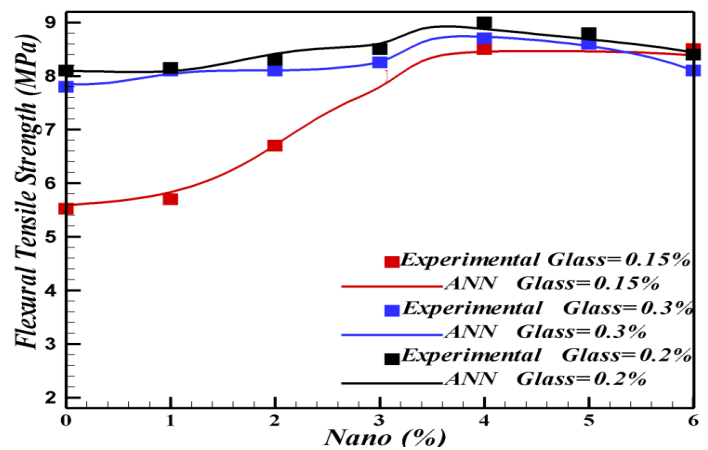

(c) Glass fibers.

Figure 8: Flexural strength of the samples containing: a) Steel fibers; b) PP fibers; c) Glass fibers. 


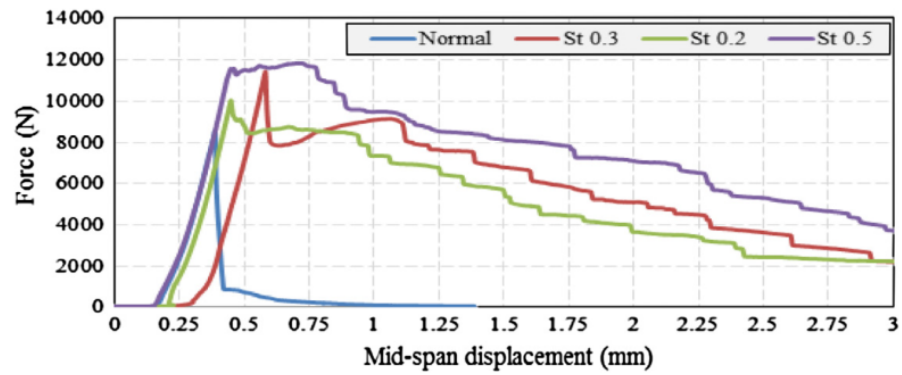

(a)

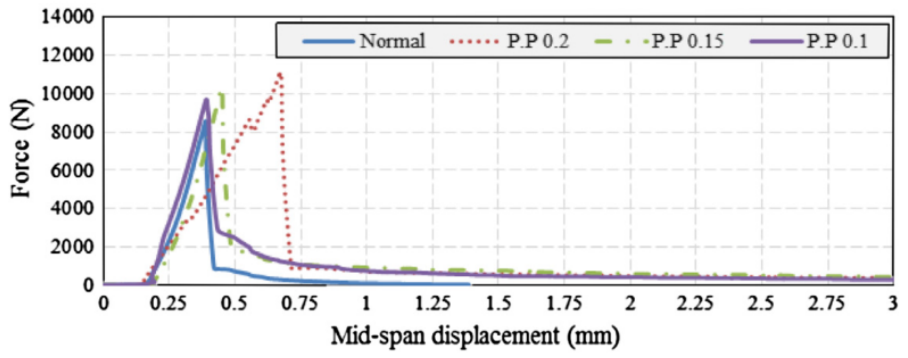

(b)

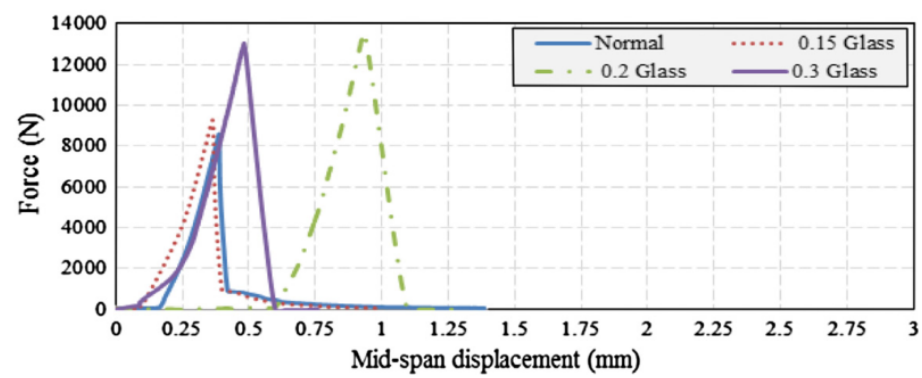

(c)

Figure 9: Force-displacement curves for samples with different contents of fibers:

(a)Steel, (b)polypropylene and (c)glass.

\subsection{Modeling of output using MLP-type neural network}

The input-output data pairs used in the present work consist of two input variables, namely the nano and fiber percent and three outputs are flexural tensile strength, tensile strength behavior and compressive strength obtained from experimental tests. Before training procedure the data set was normalized to their mean value and standard deviation 1. A training set of 25 out of 28 inputoutput data pairs is used to train the MLP-type neural network with only one hidden layer based on BP algorithm. The remaining 3 data pairs are used to test the network performance. Since there are two input variables the network has two neurons in the input layer and one neuron in the output layer. Hence there is no specific method to determine the number of neurons in the hidden layer, trial and error was used. Fig.(10) depicts the effect of different neural network architecture (different number of neurons in the hidden layer) on the RMS error of the network obtained from the normalized data. As can be seen a network with 15 neurons in the hidden layer has an acceptable performance. 


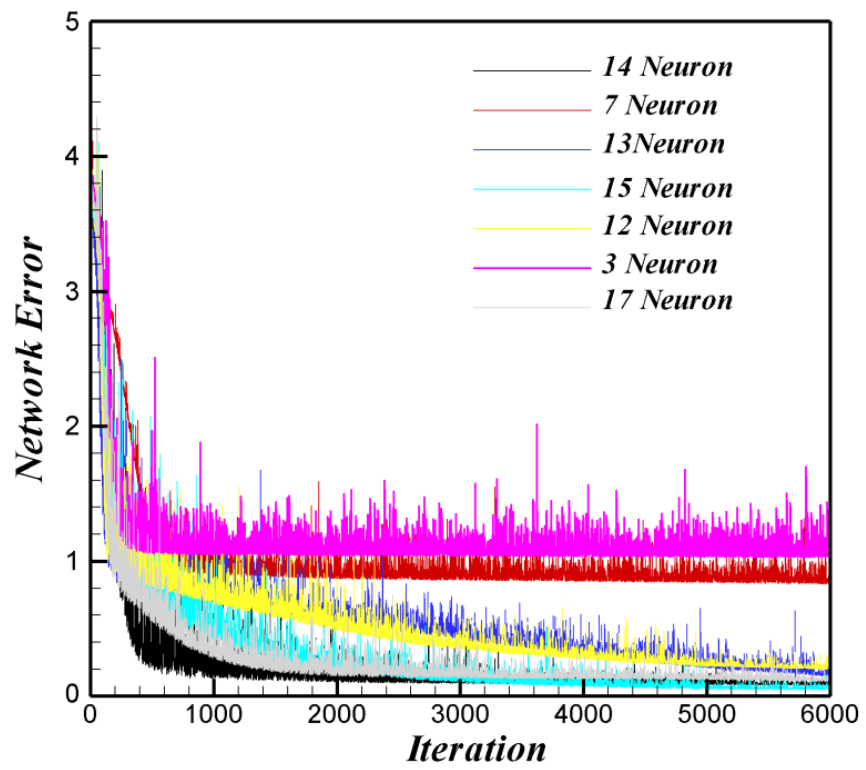

Figure 10: effects of the number of hidden neurons on the network performance for PP fiber and nano-silica particles.

The excellent behavior of the MLP-type neural network for both training and testing data for the present case is also shown in Fig. (11). The figure reveals that the trained network is able to model and predict the outputs successfully.

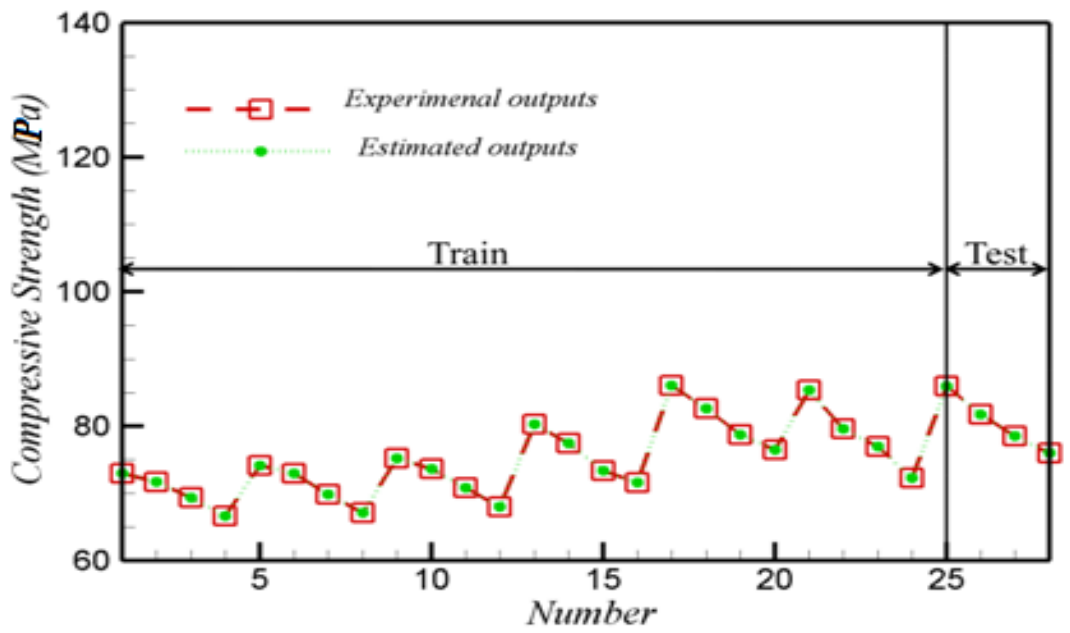

Figure 11: Performance evaluation of the neural network in prediction of $\mathrm{G}_{\mathrm{F}}$ for PP and nano-silica particles. 

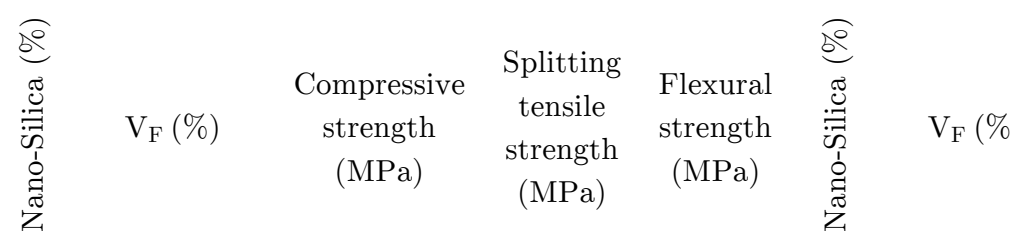

\begin{tabular}{|c|c|c|c|c|c|c|c|c|c|c|c|}
\hline \multirow{10}{*}{0} & - & & \multirow{2}{*}{$\begin{array}{c}73 \\
74.3 \\
\end{array}$} & \multirow{2}{*}{$\begin{array}{l}4 \\
5 \\
\end{array}$} & \multirow{2}{*}{$\begin{array}{l}5.16 \\
6.02 \\
\end{array}$} & \multirow{10}{*}{4} & \multicolumn{2}{|c|}{-} & 86.1 & \multirow{2}{*}{$\frac{5.4}{6.7}$} & \multirow{2}{*}{$\begin{array}{l}7.2 \\
8.4\end{array}$} \\
\hline & \multirow{3}{*}{ Steel } & 0.2 & & & & & \multirow{3}{*}{ Steel } & 0.2 & 85.7 & & \\
\hline & & 0.3 & 81.5 & 5.2 & 6.58 & & & 0.3 & 88 & 7.3 & 8.6 \\
\hline & & 0.5 & 78 & 5.8 & 7.08 & & & 0.5 & 87.2 & 7.6 & 9.1 \\
\hline & \multirow{3}{*}{$\mathrm{PP}$} & 0.1 & 71.7 & 4.2 & 5.82 & & \multirow{6}{*}{ Glass } & 0.1 & 82.6 & 5.5 & 7.5 \\
\hline & & 0.15 & 69.3 & 4.6 & 6.24 & & & 0.15 & 78.7 & 6.1 & 7.8 \\
\hline & & 0.2 & 66.6 & 4.6 & 6.6 & & & 0.2 & 76.5 & 6.3 & 7.9 \\
\hline & \multirow{4}{*}{ Glass } & 0.15 & 82 & 4.5 & 5.52 & & & 0.15 & 88.7 & 6.3 & 8.5 \\
\hline & & 0.2 & 78.5 & 5.6 & 8.1 & & & 0.2 & 84 & 7.2 & 9 \\
\hline & & 0.3 & 76.8 & 5.3 & 7.8 & & & 0.3 & 83.6 & 7.1 & 8.7 \\
\hline \multirow{10}{*}{1} & & & 74.1 & 4.1 & 5.3 & & \multicolumn{2}{|c|}{-} & 8.6 & 5.3 & 7.2 \\
\hline & \multirow{3}{*}{ Steel } & 0.2 & 75 & 5.8 & 6.2 & & \multirow{3}{*}{ Steel } & 0.2 & 85.2 & 6.7 & 8.3 \\
\hline & & 0.3 & 81.6 & 5.8 & 6.9 & & & 0.3 & 88 & 7 & 8.6 \\
\hline & & 0.5 & 78 & 6 & 7.3 & & & 0.5 & 86.8 & 7.5 & 9 \\
\hline & \multirow{3}{*}{$\mathrm{PP}$} & 0.1 & 73 & 4.2 & 5.88 & 5 & \multirow{3}{*}{$\mathrm{PP}$} & 0.1 & 81.8 & 5.5 & 7.2 \\
\hline & & 0.15 & 69.8 & 4.7 & 6.3 & & & 0.15 & 78.5 & 6 & 7.8 \\
\hline & & 0.2 & 67.1 & 4.8 & 6.6 & & & 0.2 & 76 & 6.3 & 7.8 \\
\hline & & 0.15 & 82.2 & 4.6 & 5.7 & & & 0.15 & 88 & 6.2 & 8.2 \\
\hline & Glass & 0.2 & 79.6 & 5.6 & 8.15 & & Glass & 0.2 & 83.2 & 7.2 & 8.8 \\
\hline & & 0.3 & 77.1 & 5.5 & 8.1 & & & 0.3 & 83 & 7 & 8.6 \\
\hline & - & & 75.2 & 4.3 & 5.52 & & - & & 85.4 & 5.4 & 7.17 \\
\hline & & 0.2 & 77.5 & 5.8 & 7.2 & & & 0.2 & 85.2 & 6.5 & 8.4 \\
\hline & Steel & 0.3 & 82.7 & 7.1 & 7.53 & & Steel & 0.3 & 86.7 & 7.2 & 8.5 \\
\hline & & 0.5 & 79.2 & 6.9 & 7.4 & & & 0.5 & 86.1 & 7.3 & 8.8 \\
\hline 2 & & 0.1 & 73.6 & 4.4 & 6.1 & 6 & & 0.1 & 79.6 & 5.4 & 7.1 \\
\hline 2 & $\mathrm{PP}$ & 0.15 & 70.8 & 5 & 6.4 & 6 & PP & 0.15 & 77 & 5.8 & 6.9 \\
\hline & & 0.2 & 68 & 5.4 & 7 & & & 0.2 & 72.3 & 6 & 7.2 \\
\hline & & 0.15 & 82.6 & 4.8 & 6.7 & & & 0.15 & 86.5 & 6 & 8.5 \\
\hline & Glass & 0.2 & 80.5 & 5.7 & 8.3 & & Glass & 0.2 & 83 & 6.8 & 8.4 \\
\hline & & 0.3 & 78.7 & 5.5 & 8.1 & & & 0.3 & 82.7 & 6.7 & 8.1 \\
\hline & - & & 80.3 & 5 & 6 & & & & & & \\
\hline & & 0.2 & 82.5 & 6.2 & 7.7 & & & & & & \\
\hline & Steel & 0.3 & 84.7 & 7.1 & 7.9 & & & & & & \\
\hline & & 0.5 & 84.5 & 7.1 & 8.5 & & & & & & \\
\hline 3 & & 0.1 & 77.5 & 5.1 & 7 & & & & & & \\
\hline 3 & $\mathrm{PP}$ & 0.15 & 73.4 & 5.8 & 7.5 & & & & & & \\
\hline & & 0.2 & 71.6 & 6.1 & 7.7 & & & & & & \\
\hline & & 0.15 & 84.7 & 5.5 & 8 & & & & & & \\
\hline & Glass & 0.2 & 83.5 & 6 & 8.5 & & & & & & \\
\hline & & 0.3 & 83 & 6 & 8.25 & & & & & & \\
\hline
\end{tabular}

Table 3: Physical properties of the hardened concrete (28days).

Latin American Journal of Solids and Structures 11 (2014) 1906-1923 


\section{CONCLUSIONS}

In this paper an MLP-ANN was used to estimate the combined effects of fibers and nano-silica on the mechanical Properties (flexural tensile strength, tensile strength behavior and compressive strength) of SCC. From this investigation, some conclusions can be summarized as follows:

Fibers are very strong under tension or bending-induced tension. Having this property in mind and evaluating the results of the compressive assessments, it can be concluded that. An increase in the number of fibers per volume unit of concrete initially increases the strength and consequently formability of the samples up to the splitting point. Any further increase of the fibers can result in fiber balling. In this condition, fibers are not only helpful, but also make holes and pores in the mixture.

Mechanical properties such as compressive, flexural and tensile strength are initially increased by the increase of nano-silica content up to $4 \mathrm{wt} \%$ and then decreased. The increase in strength is because of nano-silica pozzolanic reactions while its decrease is because of high specific surface of nano-particles. When the content of nano-particles increases beyond a certain value (optimal percentage), they will stick to each other through a physical reaction leading unstable balls. An increase of $4 \mathrm{wt} \%$ of nano-silica is considered as optimal value in this experimental study.

Concretes with different fibers showed different mechanical properties. In case of metal fiber reinforced concrete, increasing the fiber up to $3 \mathrm{~V} \%$ initially increases the compressive strength up to amaximum value and then decreases the compressive strength, while flexural and tensile splitting strengths follow a relatively linear increment. In polypropylene fibers-reinforced concrete, by increasing the percentage of fibers, compressive strength decreases while flexural and tensile strengths increases. In the glass fiber-reinforced concrete, compressive strength was totally higher than the reference specimen; however, increase of fiber content, decreases compressive strength and increases the flexural and tensile strengths.

Findings of the flexural assessments among the mixtures showed that increasing the content of fibers, especially metal fiber, increases the tensile and flexural strengths and therefore, the consequent formability is significantly increased. Moreover, increase of the nano-silica content up to 4 wt\%, enhances the tensile and flexural strengths more significantly which is because of the filling and pozzolanic effects of nano-silica in contact area between fibers and cement matrix.

In order to predict the compressive strength, tensile strength behavior and flexural tensile strength, models were constructed by MLP-ANN method.

The comparison revealed that the obtained results from ANN are in a good agreement with the experimental ones.

\section{References}

Al-Rousan.R, R. Haddad, K. Al-Sa'di, Effect of sulfates on bond behavior between carbon fiber reinforced polymer sheets and concrete, Materials \& Design, 43, (2013), pp. 237-248.

Amr S. El-Dieb, Mechanical, durability and microstructural characteristics of ultra-high-strength self-compacting concrete incorporating steel fibers, Materials \& Design,30, Issue 10, (2009), pp. 4286-4292.

Arslan MH. Application of ANN to evaluate effective parameters affectingfailure load and displacement of RC buildings. Nat Hazards Earth SystSci J2009;9:967-77 
Arslan MH, Ceylan M, Kaltakcı MY, Ozbay Y, Gulay G. Prediction of forcereduction factor R of prefabricated industrial buildings using neural networks. StructEngMech 2007;27(2):117-34

Beigi Morteza H., Javad Berenjian, Omid Lotfi Omran, Aref Sadeghi Nik, Iman M. Nikbin, An experimental survey on combined effects of fibers and nanosilica on the mechanical, rheological, and durability properties of selfcompacting concrete, Materials \& Design, 50, (2013), pp.1019-1029.

Bencardino.F, L. Rizzuti, G. Spadea, R.N. Swamy. Experimental evaluation of fiber reinforced concrete fracture properties, Composites: Part B 41 (2010),pp17-24.

Collepardi M, Ogoumah Olagot J, Troli R, Simonelli F, Collepardi S. Combination of silica fume, Fly Ash and Amorphous Nano-Silica in Superplasticized High-Performance Concretes, Enco, Engineering Concrete, Ponzano Veneto, Italy, (2007).

DTI, Best Practice Guidelines for Developing Neural Computing Applications, 1994.

Flood I, Muszynski L, Nandy S. Rapid analysis of externally reinforced concrete beams using neural networks. ComputStruct 2001;79:1553-9.

Goh ATC. Prediction of ultimate shear strength of deep beams using neuralnetworks. ACI Struct J 1995;92(1):2832 .

Guang NH, Zong WJ. Prediction of compressive strength of concrete by neuralnetworks. CemConcr Res 2000;30:1245-50.

Holschemachera.K, T. Muellera, Y. Ribakov, Effect of steel fibres on mechanical properties of high-strength concrete, Materials \& Design, 31, Issue 5, (2010), pp. 2604-2615.

Huang Gu, Zuo Zhonge, Compressive behaviour of concrete cylinders reinforced by glass and polyester filaments, Materials \& Design, 26, Issue 5, (2005), pp. 450-453.

Ivorra.S, P. Garcés, G. Catalá, L.G. Andión, E. Zornoza, Effect of silica fume particle size on mechanical properties of short carbon fiber reinforced concrete, Materials \& Design,31, Issue 3, (2010), pp.1553-1558.

Jamal A, Abdalla A, Elsanosi A. Abdelwahab. Modeling and simulation of shearresistance of R/C beams using artificial neural network. J Franklin Inst2007;344:741-56.

Lin,Wei-ling. Toughness 1922behavior of fiber reinforced concrete, Fiber Reinforced Cement and Concrete, Proceedings of the Fourth RILEM International symposium, Sheffield, UK, (1992), pp.299-315.

Majid Ali, Xiaoyang Li, Nawawi Chouw, Experimental investigations on bond strength between coconut fibre and concrete, Materials \& Design, 44, (2013), pp. 596-605.

Mohammadi.Y, R. Carkon-Azad, S.P. Singh, S.K. Kaushik. Impact resistance of steel fibrous concrete containing fibres of mixed aspect ratio, Construction and Building Materials, 23,(2009), pp. 183-189.

Mohammadi.Y, S.P. Singh b, S.K. Kaushik. Properties of steel fibrous concrete containing mixed fibres in fresh and hardened state. Construction and Building Materials, 22,(2008), pp. 956-965.

NajiGivi.A, Suraya Abdul Rashid, Farah Nora A. Aziz, MohamadAmranMohdSalleh. The effects of lime solution on the properties of $\mathrm{SiO} 2$ nanoparticles binary blended concrete, Composites: Part B, 42, (2011),pp.562-569.

Ali Nazari, ShadiRiahi. The effects of $\mathrm{SiO} 2$ nanoparticles on physical and mechanical propertiesof high strength compacting concrete, Composites: Part B, 42, (2011),pp.570-578.

Okamura H, Ozawa K. Self-Compactable high performance concrete in japan, International Workshop on High Performance Concrete, SP 169, American Concrete Institute, Farmington Hills, MI, (1994), pp. 31-44.

Okamura H. Self Compacting High-Performance Concrete, Concrete International, (1997), pp. 50-54.

Olivito. R.S., F.A. Zuccarello. An experimental study on the tensile strength of steel fiber reinforced concrete. Composites: Part B 41, (2010), pp 246-255.

Ozawa K, Maekawa K, Okamura H. Self-Compacting high-performance concrete, Collected Papers (University of Tokyo: Department of Civil Engineering), 34, (1996), pp. 135-149. 
Pannirselvam N, Raghunath PN, Suguna K. Neural network for performance of glass fibre reinforced polymer plated RC beams. Am J EngApplSci 2008:183-8.

Perera R, Barchin M, Artega A, De Diego A. Prediction of the ultimate strength of reinforced concrete beams FRPstrengthened in shear using neural networks. Compos Part B Eng 2010;41:287-98.

Qing Y, Zenan Z, Li S, Rongshen C. A comparative study on the pozzolanic activity between nano-SiO2 and silica fume. J Wuhan UnivTechnol - Mater Sci Ed, 21(3), (2008), pp.153-7.

Qing Y, Zenan Z, Deyu K, Rongshen C. Influence of nano-SiO2 addition on properties of hardened cement paste as compared with silica fume. Construction and Building Materials,21(3), (2007),pp.539-45.

Sanad A, Saka MP. Prediction of ultimate shear strength of reinforced concretedeep beams using neural networks. J StructEng, ASCE 2001;127(7):818-28.

Seddik Meddah.M, Mohamed Bencheikh. Properties of concrete reinforced with different kinds of industrial waste fibre materials, Construction and Building Materials,23, (2009), pp. 3196-3205.

Seung Hun Park, Dong Joo Kim, Gum Sung Ryu, Kyung TaekKoh. Tensile behavior of Ultra High Performance Hybrid Fiber Reinforced Concrete, Cement \& Concrete Composites, 34, (2012), pp.172-184.

Shekari. A. H., M.S. Razzaghi. INFLUENCE OF NANO PARTICLES ON DURABILITY AND MECHANICAL PROPERTIES OF HIGH PERFORMANCE CONCRETE, Procedia Engineering, 14, (2011),pp.3036-3041.

Soroushian p. Secondary reinforcement adding cellulose fibers, ACI, Concrete International, (1986), pp. 28-38.

Su-Tae Kang, Yun Lee, Yon-Dong Park c, Jin-Keun Kim. Tensile fracture properties of an Ultra High Performance Fiber Reinforced Concrete (UHPFRC) with steel fiber. Composite Structures,92, (2010),pp.61-71.

Tumadhir Merawi Borhan, Properties of glass concrete reinforced with short basalt fibre, Materials \& Design, 42, (2012), pp. 265-271.

Tavakoli H.R, Lotfi O, Soleimani S, Falahtabar Shiade M, Prediction of Energy Absorption Capability in Fiber Reinforced Self-Compacting Concrete Containing Nano-Silica Particles using artificial neural network, Latin American Journal of Solids ans Structures, 11,(2014), pp.966-972.

Werbos P.J., Beyond regression: New Tools for Prediction and Analysis in the Behavioural Sciences, Ph.D. Thesis, Harvard University, 1974.

Xu.Z, H. Haoa, H.N. Lib, Dynamic tensile behaviour of fibre reinforced concrete with spiral fibres, Materials \& Design, 42, (2012), pp.72-88.

Xua.Z, b, H. Haoa, H.N. Lib, Experimental study of dynamic compressive properties of fibre reinforced concrete material with different fibres, Materials \& Design, 33, (2012), pp.42-55.

Yang KH, Ashour AF, Song JK, Lee ET. Neural network modelling for shearstrength of reinforced concrete deep beams. Struct Build 2008;161(1):29-39. 